\title{
Múltiplas avaliações para aquisição de cadeiras de escritório: favorecendo a saúde no trabalho*
}

\section{Multiple assessments for the purchase of office chairs: favoring health at work}

\author{
Bárbara Iansã de Lima Barrosoํㅜ, Cláudia Regina Cabral Galvão
}

http://dx.doi.org/10.11606/issn.2238-6149.v26i1p136-145

Barroso BIL, Galvão CRC. Múltiplas avaliações para aquisição de cadeiras de escritório: favorecendo a saúde no trabalho.Rev Ter Ocup Univ São Paulo. 2015 jan./abr.;26(1):136-45.

RESUMO: Na busca para definir a melhor cadeira de escritório utilizada em terminais informatizados de uma autarquia do município de Manaus/AM, é descrito neste estudo, um processo metodológico de construção para identificar a melhor cadeira para o trabalho informatizado utilizando múltiplas avaliações: entrevistas estruturadas; mapa de sensação de desconforto e dor proposto por Corlett e Wilson ${ }^{22}$; e questionários de avaliação por escala sobre a satisfação da cadeira, aplicadas com 71 trabalhadores. Neste estudo caracterizado como exploratório, aplicado, qualitativo e quantitativo, analisou-se estatisticamente dados aferidos em escala, e a opinião espontânea dos participantes na testagem de duas cadeiras. Observou-se que a escolha da cadeira apropriada para o posto de trabalho, na função dos participantes, englobou cadeiras com rodízios e regulagem do assento e encosto, o que pode contribuir para melhoria da produtividade e reduzir o efeito de doenças do trabalho associadas à postura sentada.

DESCRITORES: Engenharia humana; Transtornos traumáticos cumulativos; Desenho/normas; Postura/fisiologia; Local de trabalho/normas; Questionários.
Barroso BIL, Galvão CRC. Multiple assessments for the purchase of office chairs: favoring health at work. Rev Ter Ocup Univ São Paulo. 2015 jan./abr.;26(1):136-45.

\begin{abstract}
In the quest to finding the best office chair used in terminals of the municipality of Manaus/AM, this study describes a methodological construction process to identify the best chair for computer work using multiple assessments: structured interviews; as well as the discomfort and pain map proposed by Corlett and Wilson $^{22}$; and scale for evaluation questionnaires on satisfaction of the chair, which were applied to 71 workers. In this study characterized as exploratory, qualitative and quantitative, data was analyzed statistically in scale, and the spontaneous opinion of the participants in testing two chairs. It was observed that the choice of the appropriate chair for the job included chairs with casters and adjustments of the seat and backrest, which can contribute to improved productivity and reduce the effect of occupational diseases associated with posture sitting.
\end{abstract}

KEYWORDS: Human engineering; Cumulative trauma disorders; Design/standards; Posture/physiology; Workplace/standards; Questionnaires.

\footnotetext{
* Artigo inédito elaborado a partir de dados coletados para dissertação de Mestrado realizada na Faculdade de Tecnologia no Programa de Pós-graduação em Engenharia de Produção da Universidade Federal do Amazonas com o título: Avaliação da sensação de desconforto e de dor durante a postura sentada: uma análise em terminais informatizados, em 2010. Orientada pela Professora Doutora Silvana Dacol (in memoriam).

1. Mestre em Engenharia de Produção pela Universidade Federal do Amazonas. Professora Assistente do Departamento de Terapia Ocupacional da Universidade Federal da Paraíba. João Pessoa, PB. E-mail: barbarabarroso@yahoo.com.br.

2. Mestre em Engenharia de Produção pela Universidade Federal do Rio Grande do Norte. Professora Assistente do Departamento de Terapia Ocupacional da Universidade Federal da Paraíba, João Pessoa, PB.

Endereço para correspondência: Bárbara Barroso. Centro de Ciências da Saúde, Departamento de Terapia Ocupacional da Universidade Federal da Paraíba, Campus Universitário I. Bairro: Cidade Universitária, João Pessoa, PB. CEP: 58059-900.
} 


\section{SAÚDE, TRABALHO, HISTÓRICO E NOVAS FRONTEIRAS}

$\mathrm{A}$ relação entre o trabalho e o processo saúde/ doença existe desde a antiguidade, tendo sido exacerbada a partir da Revolução Industrial ${ }^{1}$. O conceito da "saúde do trabalhador" foi gerado a partir do processo de evolução industrial e aumento da quantidade de doenças ocupacionais que emergiu durante esta revolução, bem como o impacto das atividades produtivas na saúde da massa de trabalhadores, regidapelo contrato de trabalho, que passou a ser submetido às regras que priorizavam a eficiência e a perpetuação dos processos de manufatura, independentemente do adoecimento ou não da mão de obra trabalhadora.

Durante o período da Revolução Industrial, o operário livre era aquele que podia vender sua força de trabalho. Esse indivíduo tornou-se "presa" das máquinas, de seus ritmos, dos ditames da produção que atendiam à acumulação rápida de capital e o máximo aproveitamento dos equipamentos que eram substituídos para acelerar o processo produtivo. Assim, surgem as primeiras doenças relacionadas ao trabalho.

Os Distúrbios Osteomusculares Relacionados ao Trabalho (DORT), principalmente as patologias de ordem postural têm sido consideradas um sério problema de saúde pública, pois atinge alta incidência da população economicamente ativa mundialmente, seja pela sua prevalência na população trabalhadora; pela abrangência dos diversos setores da economia implicados e impactados; ou até mesmo pela complexidade clínica que envolve o alto custo da terapêutica medicamentosa e do processo reabilitador, incapacitando-o temporariamente ou definitivamente para determinadas atividades profissionais ${ }^{2}$.

Os DORT são grupos heterogêneos de distúrbios funcionais e/ou orgânicos gerados pela falta de tempo na recuperação pós-contração do músculo, induzido por fadiga neuromuscular, causado por uma quantidade excessiva de uma determinada função e/ou atividade desempenhada durante a jornada de trabalho, ocasionando cansaço no membro utilizado, diminuição da flexibilidade, edema, eritema, entre outros sinais e sintomas. A permanência prolongada na postura sentada aumenta os riscos de incidência das patologias associadas à postura ${ }^{3}$.

O Ministério da Previdência Social/Instituto Nacional do Seguro Social (MPS/INSS), em associação com o Ministério do Trabalho e Emprego (MTE), tendo como fonte a Comunicação de Acidentes de Trabalho (CAT), publicada em 2012, no Anuário Estatístico de Acidente de Trabalho (AEAT), registrou aproximadamente 705.239 acidentes de trabalho no período no ano de 2012, e no triênio 2010-2012, um total de 2.135.338 milhões de trabalhadores com registro em CAT em todo território nacional ${ }^{4}$.

Daldon e Lancman ${ }^{5}$ destacam a importância do desenvolvimento de intervenções que busquem garantir condições durante os processos de trabalho, de forma digna e segura, minimizando os ricos de surgimento de problemas de saúde relacionados ao trabalho.

Entende-se que a saúde do trabalhador é uma área passível de abrigar diferentes aproximações, incluir diversos profissionais, estudos e práticas de valor imensurável ${ }^{6}$. Esse fato cria uma zona de empatia para a qual confluem diversos estudos disciplinares, entre os quais, os da terapia ocupacional, engenharia de produção, ergonomia, tecnologia assistiva, saúde pública, reabilitação profissional, entre outros; como forma deatender as questões relativas àsaúde no trabalho, e preservar a compreensão da complexidade e enfrentamento dos problemas ocasionados pelos ditames da produtividade.

A Ergonomia tem sido difundida de forma eficiente nos dias de hoje. A quantidade de publicações nesta área, tanto nacionais como internacionais, tem crescido significativamente, porém, a sua aplicação no desenvolvimento de produtos ainda não é proporcional ao seu crescimento. Isso pode ser confirmado quando, ainda hoje, inúmeros produtos são projetados sem considerar os fatores humanos causando constrangimentos aos seus usuários. Resulta muitas vezes, em baixo desempenho, fisiopatologias e até descarte destes ${ }^{7}$.

De acordo com Lancman e Ghirardi ${ }^{8}$ pensar em uma intervenção voltada à prevenção implica em programar ações com potência para mobilizar micro transformações sociais. Tais mudanças, a partir de medidas preventivas, tornam a saúde do trabalhador um ponto focal na indústria produtiva nacional, resgatando o desejo à saúde plena dos trabalhadores.

Neste estudo será correlacionada, a associação da postura sentada com a utilização de um suporte, a cadeira de escritório. Para a realização desta pesquisa, a organização escolhida foi uma autarquia que funciona como entidade auxiliar da administração pública autônoma e descentralizada que faz parte da Zona Franca de Manaus (ZFM), criada em 1967 para estimular a industrialização do município e áreas adjacentes na região Norte do país.

A investigação foi motivada pela constante demanda de selecionar uma cadeira adequada para os trabalhadores da Coordenação de Análise Documental (CODOC), setor responsável por permitir que empresas instaladas no Polo Industrial de Manaus (PIM) antecipem por meio de envio de arquivo eletrônico, os dados da documentação fiscal 
que acobertam as mercadorias com destino a Amazônia Ocidental e Macapá-AP, utilizando como meio o Sistema de Internamento de Mercadoria Nacional (SINAL).

Com o crescimento dos números de postos de trabalhos na Autarquia, associados aos números crescentes do PIM, fizeram com que surgisse a necessidade de novos funcionários, suprindoquantidade da entrada de notas pelo SINAL.

\section{OBJETIVOS DO ESTUDO}

Esta pesquisa possui como objetivo responder, diante da especificidade do contexto produtivo analisado, mostrando ser viável a avaliação de produtos a partir da utilização de múltiplas avaliações durante a execução da atividade laboral, utilizando dois modelos de cadeiras disponíveis na autarquia pesquisada, como forma de avaliar se as características dimensionais e de design, asseguram o assento adequado para o desenvolvimento do trabalho em terminais informatizados.

O local específico para a realização dessa pesquisa foi a CODOC. O setor pesquisado foi escolhido devido ao tipo de atividade desempenhada pelos colaboradores estar dentro das expectativas do estudo.

O trabalho realizadono setor baseia-se em três fases:

I - Analisar a documentação fiscal relativa ao ingresso e internamento de mercadoria nacional;

II - Identificar, dentre a documentação analisada, aquelas aptas a usufruir dos incentivos fiscais da ZFM, e;

III - Classificar as notas fiscais a serem internadas pela Autarquia, e prover os dados necessários a sua geração.

A escolha para a realização da pesquisa baseou-se na necessidade de diminuir os índices de DORT notificados formalmente neste setor, já que existiam inúmeras queixas de dores e desconforto ao longo da jornada laboral e uma grande insatisfação por parte dos funcionários relacionadas as cadeiras de trabalho.

\section{PROCEDIMENTOS METODOLÓGICOS}

Este artigo originou-se de uma pesquisa iniciada em 2010 em Manaus-AM, vinculada a uma dissertação de mestrado $^{10}$ desenvolvida no Programa de Pós-graduação em Engenharia de Produção da Universidade Federal do Amazonas (UFAM) e aprimorada após aprofundamento bibliográfico entre os anos de 2011 a 2014 no Laboratório de Saúde, Trabalho e Ergonomia (LASTE) da Universidade Federal da Paraíba (UFPB).

A metodologia ergonômica utilizada durante a realização desta pesquisa busca encontrar a relação do usuário com o produto, para definir parâmetros de usabilidade entre ambos. Para obtenção dos dados, foram executadas observações da atividade realizada no período da jornada de trabalho, de forma a perceber a relação entre a cadeirae o tipo de postura adotada pelo trabalhador.

Quanto à sua abordagem, possui caráter qualitativo e quantitativo, e considera tanto a análise estatística de dados aferidos em escala, quanto à opinião dos indivíduos envolvidos na pesquisa.

Em relação aos objetivos, essa pesquisa é classificada como exploratória, pois visa uma maior familiaridade com o problema de avaliação de cadeiras investigadas.

De acordo com os critérios de classificação de Silva e Menezes ${ }^{11}$, esse estudo, quanto à natureza, é classificado como aplicado, pela geração de conhecimentos dirigidos à soluções de problemas específicos do setor pesquisado, cadeiras para trabalhos em terminais informatizados.

Do ponto de vista dos procedimentos técnicos, foi realizada uma revisão bibliográfica, com o intuito de conhecer melhor o problema, construir o referencial teórico e determinar as variáveis da pesquisa. A estratégia utilizada para revisão de literatura compreendeu na efetivação de buscas sistemáticas, a partir das bases de dados Bireme, PubMed e Cochrane. Os descritores utilizados foram: ergonomia, saúde do trabalhador, e design de mobiliário e equipamento. As buscas por artigos disponíveis foram finalizadas em março de 2013. Não foram utilizados filtros de data, pois pretendeu-se realizar uma revisão de todos os estudos publicados até a atualidade.

A pesquisa foi realizada através da aplicação de entrevista estruturada e semiestruturada, executada pelo pesquisador numa sala separada ao local de realização da atividade de trabalho.

A amostra foi constituída por 71 colaboradores, 45 do sexo feminino (63\%) e 26 do sexo masculino (37\%); a média de idade era de 27,5 anos para as mulheres e 35,8 anos para os homens, perfazendo um total de $100 \%$ dos trabalhadores do setor estudado.

Foram realizadas 71 entrevistas individuais com duração média de 22 minutos. Todos os colaboradores exerciam a função de digitadores, trabalhando em turnos de seis horas, com pausa de 15 minutos, e micro pausa a cada 50 minutos de trabalho.

Os resultados foram tabulados em uma planilha eletrônica de acordo com o total de nível de desconforto e conforto das duas cadeiras, descritas como cadeira A e cadeira B, ressaltando, que cada experimento foi realizado durante o mesmo dia de trabalho.

O problema levantando nessa pesquisa refere-se 
à caracterização da proposta de sugerir orientações para a definição, seleção e avaliação de cadeiras de escritório utilizadas em terminais informatizadoscomo ferramenta de análise para essa pesquisa, avaliações simples, concisas e de fácil aplicação.

A importância das avaliações de sensação de desconforto e dor durante a jornada ocupacional originou-se dos altos índices de afastamento por DORT, descritos nas pesquisas desenvolvidas por Iida e Pazzeto ${ }^{12}$ e Guimarães ${ }^{13}$, sobre a importância do mobiliário apropriado para cada função exercida de acordo com a literatura ${ }^{11,12,13,14,15,16,17}$.

\section{Caracterização do estudo}

Como forma de identificara possível ocorrência de dores e desconforto geradoras de doenças ocupacionais no setor pesquisado, determinados a partir do uso de mobiliário inadequado. Durante a realização da pesquisa o voluntário foi orientado a desempenhar a mesma atividade de conferência e digitação de notas fiscais. O processo de entrada e saída de notas começava primeiramente com a avaliação e depois digitação do código geral no SINAL.

A observação e o acompanhamento da atividade desenvolvida pelo trabalhador, caracteriza-se como forma elementar de avaliação dos possíveis riscos ocupacionais que envolve o indivíduo utilizando os dois modelos de cadeiras disponíveis no local de trabalho, usados durante a realização dessa pesquisa. Para isso, os critérios de inclusão dos participantes desse estudo foram: I-Ser colaborador ou servidor do setor; II - Estar acima de 12 meses na mesma atividade; III - Não estar em processo de reabilitação; IV - Não tomar medicamentos que altere seu comportamento psicológico ou seu desempenho físico; e V-Participar voluntariamente.

Todos os voluntários foram identificados por numeração para garantir o seu anonimato. Salienta-se que esta pesquisa não passou pelo Comitê de Ética, devido àregulamentação anterior do Programa de Pós-Graduação em que foi desenvolvido. Os colaboradores participantes do estudo assinaram o Termo de Consentimento Livre e Esclarecido, não sendo permitido registro fotográfico do local nem da atividade.

$\mathrm{Na}$ atualidade as normas preveem dimensões e utilização de componentes para garantir a qualidade física das cadeiras comercializadas no Brasil de acordo com as normas da ABNT $^{18}$; Floyd $^{19}$; e Brasil ${ }^{20}$, como forma de garantir segurança, conforto, usabilidade e durabilidade. Um bom assento deve promove uma boa adaptação durante a posição sentada, minimizando os ciclos de dor e desconforto durante o trabalho, fator esse ápice para a elaboração desse estudo.
O desconforto é um indicador de risco, usado para detectar possíveis problemas corporais. Suas causas são inúmeras, como, tensão musculoesquelética; compressão tecidual; fadiga muscular; déficit de circulação sanguínea e parcial isquemia; desobstrução dos nervos ocasionando pressão; e inflamações secundárias ${ }^{21}$.

Devido este estudo ser direcionadoao conhecimento das cadeiras de escritório usadas no setor pesquisado, bem como, ao estudo da interface trabalhador - SAP, e sua percepção física/sensorial relacionada à cadeira, foram utilizadas três avaliações.

\section{Primeira avaliação - Perfil do Trabalhador Através de Entrevista Estruturada}

Nesta etapa foi aplicado um formulário para coleta de dados de identificação (nome, sexo e idade) e medidas de peso e altura.

\section{Segunda avaliação - Escala de Avaliação de Níveis de Desconforto Corporal}

A Escala de Avaliação de Níveis de Desconforto Corporal (EANDC) estruturado a partir de um mapa corporal proposto por Corlett e Wilson ${ }^{22}$, e utilizado em diversas pesquisas como forma de avaliar os níveis de desconforto corporal. O mapa divide o corpo em segmentos para facilitar a localização de áreas de dores e desconforto envolvidas numa dada atividade motora. Essa avaliação utiliza uma escala linear de intensidade que varia de 0 (nenhuma dor) a 10 (muita dor). A EANDC pode ser um recurso de baixo custo e durante avaliação de níveis de desconforto, refletindo na ineficiência da usabilidade dos produtos.

O mapa de regiões corporais aplicado nesse estudo analisou vinte e duas regiões distribuídas em duas grandes áreas: membros superiores e inferiores (esquerdo e direito). Cada voluntário podia responder somente uma vez ao questionário, não havendo repetição.

A escolha dessa avaliação se deu pela facilidade e custo do instrumento, apesar de na atualidade existirem software que realizam escaneamento corporal a partir da sensação de desconforto e dor, sua manipulação e utilização ainda é restrita devido os valores de mercado e a alta complexidade em sua efetiva execução.

\section{Terceira avaliação - Satisfação da cadeira através de entrevista semiestruturada}

As cadeiras A e B foram apresentadas aos 
participantes, que também tomaram conhecimentosobre oquestionáriosubdividido em três partes: identificação da cadeira que estava sendo testada (se era A ou B); identificação do voluntário (número de identificação, idade, data e gênero); a marcação em uma escala linear de $15 \mathrm{~cm}$, correspondente ao nível de conforto percebido. Nessa escala, a extremidade direita indicava um nível muito confortável e a esquerda representava um nível de pouco conforto.

Os participantes da pesquisa tinham total liberdade para a realização de ajustes no seu SAP, como altura, inclinação, aprofundamento do encosto e assento.

\section{RESULTADOS}

A pesquisa foi realizada através da aplicação de entrevista estruturada e semiestruturada. Os resultados foram tabulados em uma planilha eletrônica de acordo com o total de nível de desconforto e conforto após utilização das duas cadeiras, descritas como cadeira A e cadeira B, em dias alternados de trabalho. Todos os colaboradores exerciam a função de digitadores, trabalhando em turnos de seis horas, com pausa de 15 minutos, e micro pausa a cada 50 minutos de trabalho.

Para comparação dos resultados das cadeiras, bem como, a definição de quais os elementos de design resultavam na maior satisfação dos usuários com os critérios estabelecidos (conforto, segurança, design e dispositivos), foram divididos os dados a seguir.

\section{Cadeira $A$}

Verificou-se que, após uso por seis horas de trabalho, a maioria dos colaboradores faziam poucas queixas com relação ao uso dacadeira em teste. Essas se referiam principalmente aos itens: 1 ) joelho (esquerdo: 1,4\%; direito: $14,10 \%$ ); 2) tornozelo (esquerdo: 7,0\%; direito: 4,2\%).

Uma das possíveis razões para tal achado reside no fato, comprovado durante a visita para aplicação do questionário, no qual a maioria dos colaboradores utilizava a cadeira elevada mantendo os pés em flutuação, sem apoio plantar. Outro possível motivo pode estar associado à bancada de suporte do terminal informatizado, que não era adequada, segundo as dimensões da Norma Regulamentadora NR-17 (2002) ${ }^{18}$, estudos futuros focando na importância de mesas e bancadas serão necessários para comprovar tal hipótese.

\section{Cadeira B}

Em relação ao experimento B, observa-se que no fim do turno as maiores queixas se concentraram no: 1) ombro (esquerdo: 29,6\%; direito: 36,6\%); 2) braço (25,4\%; 40,8\%); 3 ) antebraço $(15,5 \% ; 24,3 \%)$ e 4$)$ punho $(23,9 \% ; 28,2 \%)$.

Observa-se que a cadeira em análise apresenta os maiores valores médios na escala (nos membros superiores), quando comparado com a outra cadeira da amostra.

Realizando uma análise comparativa dos resultados das cadeiras A e B, percebe-se que alguns itens estão relacionados intrinsecamente ao fato que a cadeira $\mathrm{B}$ possuía apoio para braços sem ajustes de altura, enquanto a cadeira $\mathrm{A}$ não dispunha desse acessório. Dessa forma, a configuração da cadeira A não interferiano desempenho do trabalhadordurante a execução da tarefa de sentar e levantar, aproximar a cadeira da mesa, além de diminuir os choques por contato do cotovelo no apoio de braços.

Outro fator associado ao elevado número de dores e desconforto, prevalente nos membros superiores direito, vistos em todos os procedimentos analisados, pode estar associado com a dominância de lateralidade dos digitadores, ou seja, todos os indivíduos analisados eram destros. Este fato certamente explica o motivo pelo qual em momento algum os escores obtidos pelo membro superior esquerdo (MS-E) foi superior aos obtidos pelo membro superior direito (MS-D).

\section{As cadeiras $A$ e $B$}

Neste item a análise dos resultados é direta, através da média aritmética dos valores individuais. $\mathrm{O}$ resultado final da análise da entrevista aberta, realizada antes de iniciar o experimento C, indicou a preferência de 78,4\% dos usuários pela cadeira A e 21,6\% pela cadeira B.

Após tabulação dos resultados para avaliar as regiões corporais através do questionário de desconforto e dor, verificou-se que a cadeira A apresentou o menor valor médio de queixa.

Desta forma, o resultado da entrevista aberta mostrou-se similar à avaliação das regiões corporais em ambas as cadeiras. A cadeira A foi eleita como a mais propíciapara o trabalho executado, já que o conforto percebido do assento pelos colaboradores foi notável, e as queixas de desconforto/dor foram pequenas em relação à cadeira $\mathrm{B}$, a qual foi eleita como a mais rejeitada para o setor estudado.

Em relação à demanda das características de design das cadeiras de trabalho, pode-se observar que os colaboradores preferiram as cadeiras com rodízios e regulagem de altura do assento. Para esse grupo o apoio para os braços não é importante, devido ao tipo de atividade que os mesmos desempenham (conferência e digitação de notas). A cadeira que apresentou todas estas características 
foi a cadeira A.

Este fato cria uma zona de embate entre a literatura na área de Design e Ergonomia (Tabela 1). Recomendações da literatura referentes a assentos Iida ${ }^{2}$, com as especificações das Normas, NR-1 $17^{20}$ e a NBR- $13962^{18}$ que estabelece critérios mínimos para móveis de escritórios - cadeiras - que especifica características físicas e dimensionais, bem como constitui requisitos de segurança, de ergonomia, dentre outros, os quais são necessários para se ter um assento adequado como:medidas mínimas e máximas para assento e encosto,bordas arredondadas, regulagens, apoio para braços entre outros requisitos.

Tabela 1 - Recomendações da literatura referentes a assentos. Fonte: (IIDA, 1990)

\begin{tabular}{|c|c|c|c|c|c|c|c|c|c|c|c|c|c|}
\hline \multicolumn{2}{|c|}{$\begin{array}{l}\text { DIMENSÕES DO } \\
\text { ASSENTO }\end{array}$} & $\frac{\hat{\sigma}}{\hat{\sigma}}$ & 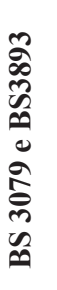 & 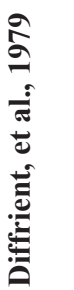 & 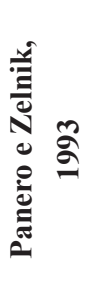 & 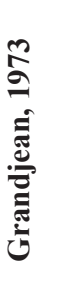 & 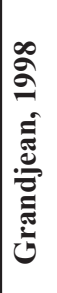 & 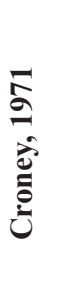 & 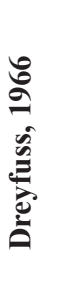 & 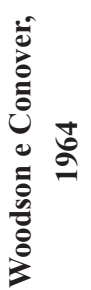 & 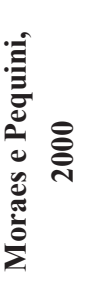 & 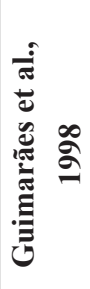 & 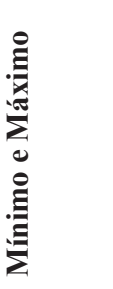 \\
\hline $\begin{array}{l}\text { Altura em } \\
\text { centímetro }\end{array}$ & $\begin{array}{l}\text { Min. } \\
\text { Max. }\end{array}$ & $\begin{array}{l}42 \\
50\end{array}$ & $\begin{array}{l}43 \\
51\end{array}$ & $\begin{array}{l}34,5 \\
52,3\end{array}$ & $\begin{array}{l}35,6 \\
50,8\end{array}$ & $\begin{array}{l}37,8 \\
52,8\end{array}$ & $\begin{array}{l}38 \\
53\end{array}$ & $\begin{array}{l}35,6 \\
48,2\end{array}$ & $\begin{array}{l}38,1 \\
45,7\end{array}$ & $\begin{array}{l}38,1 \\
45,7\end{array}$ & $\begin{array}{l}32 \\
55\end{array}$ & - & $\begin{array}{l}32-43 \\
45,7-55\end{array}$ \\
\hline $\begin{array}{l}\text { Largura em } \\
\text { centímetro }\end{array}$ & $\begin{array}{l}\text { Min. } \\
\text { Max. }\end{array}$ & 40 & 41 & 40,6 & $\begin{array}{l}43,2 \\
48,3\end{array}$ & 40 & $\begin{array}{l}40 \\
45\end{array}$ & 43,2 & 38,1 & 38,1 & $\begin{array}{l}40 \\
50\end{array}$ & $\begin{array}{l}33 \\
48\end{array}$ & $\begin{array}{l}33-43,2 \\
38,1-50\end{array}$ \\
\hline $\begin{array}{l}\text { Profundidade } \\
\text { em centímetro }\end{array}$ & $\begin{array}{l}\text { Min. } \\
\text { Max. }\end{array}$ & $\begin{array}{l}38 \\
44\end{array}$ & 36 & 38,1 & 39,4 & 40 & $\begin{array}{l}38 \\
42\end{array}$ & $\begin{array}{l}33,6 \\
38,1\end{array}$ & $\begin{array}{l}30,5 \\
38,1\end{array}$ & $\begin{array}{l}30,5 \\
38,1\end{array}$ & - & $\begin{array}{l}37 \\
43\end{array}$ & $\begin{array}{l}30,5-4- \\
38,1-47\end{array}$ \\
\hline \multirow{2}{*}{$\begin{array}{l}\text { Inclinação em } \\
\text { centímetro }\end{array}$} & Min. & 0 & 0 & 0 & - & 0 & 4 & $0-3$ & 0 & 3 & - & 0 & $0-4$ \\
\hline & Max. & 5 & 5 & 5 & - & 5 & 6 & $3-5$ & 5 & 5 & - & 10 & $5-10$ \\
\hline
\end{tabular}

Apesar das Normas Brasileiras indicarem o uso de apoio para braço com regulagens, após realização da pesquisa, percebemos que este recurso deveria ser opcional, sendo necessário apenas para os assentos que não possuem uma mesa ou bancada apropriada.

Quanto ao resultado para avaliação da satisfação dos usuários em relação ao assentoutilizado, a cadeira Aobteve a maior média, 80,6\%, enquanto a cadeira B apenas 19,4\%.

Analisando o grau de importância de cada critério de avaliação, observou-se um empate de três critérios como os mais bem avaliados: conforto, segurança e adequação ao trabalho, cada um deles com pesos iguais a $0,19 \%$.

Este resultado foi confirmado através da entrevista estruturada realizada após a utilização do experimento, quando se perguntou aos participantes da pesquisa o que os mesmos buscavam em uma cadeira de trabalho. As respostas mais frequentes foram: conforto, segurança e posição adequada para as pernas.

Finalmente, obteve-se o ranking das cadeiras, onde a cadeira A obteve a maior nota, eleita por $60,9 \%$ dos trabalhadores; e a cadeira B, $25 \%$ de escolha, considerando os que não souberam optar com $14,1 \%$.

Os estudos de Alencar e $\mathrm{Biz}^{23}$, ressaltam a importância que o trabalho tem, como papel estruturante para o ser humano, podendo comprometer a saúde nos âmbitos físico e mental. Tanto aspectos das condições, quanto da organização do trabalho, podem afetar a saúde dos trabalhadores.

Dessa forma, algumas recomendações são importantes como forma de propor melhorias das condições oferecidas no posto de trabalho, em outros locais de atuação que utilizem cadeiras que não foram previamente 
selecionadas especificamente para o uso em terminais informatizados, minimizando os efeitos da atividade no corpo físico. Tal otimização está sujeita, além de uma perfeita relação no subsistema cadeira-ferramentas de trabalho, às questões organizacionais; demais mobiliário como mesa; equipamentos como mouse e computadores; $\mathrm{e}$, àambiência física do local de trabalho.

Os critérios de avaliação de cada cadeira, associados aos fatores fisiológicos, aos comportamentais e aos demaismobiliários deveriam ser avaliados, como forma determinante para a melhoria da qualidade de vida no trabalho. Assim, recomenda-se para o setor de digitação, bem como outros setores em postos informatizados, a opção pela aquisição de cadeiras com base giratória, com regulagem de altura/inclinação de assento e encosto, espuma de boa qualidade e densidade, permitindo a adaptação antropométrica dos diversos tipos de usuários, e a possibilidade de mudanças posturais durante o seu uso. Após análise completa do ambiente de trabalho deverá ser escolhido a cadeira com apoio para braço ou não, contendo regulagem de profundidade de acordo com a tarefa executada.

\section{DISCUSSÃO}

Cadeiras mal projetadas que não consideraram os valores dimensionais dos extremos da população usuária, assim como os ângulos posturais de conforto biomecânicos incorretos podem causar desconforto, dores e propiciar o surgimento de fisiopatologias associadas ao trabalho.

Verifica-se por meio da integração entre acessibilidade, antropometria, design ergonômico, design universal, ergonomia e usabilidade, que é possível empregar soluções mais condizentes com as reais necessidades dos usuários, permitindo contemplar diversas potencialidades, que não seriam adequadamente atendidas pela ótica de uma única área do conhecimento ${ }^{24}$.

A utilização de escalas de níveis de desconforto/dor, associada ao questionário de Satisfação da Cadeira Através de Entrevista Semiestruturada, e ao Perfil do Trabalhador Através de Entrevista Estruturadapodem contribuir no processo de desenvolvimento de um produto apontando quais os subsistemas poderão causar problemas aos usuários permitindo selecionar a cadeira para escritório ideal de acordo com as normas brasileiras vigentes, associada a percepção do usuário, e que necessitam, portanto, serem ajustados.

\section{Análise das partes das cadeiras $A$ e $B$}

\section{Base A}

Em relação ao requisito base, a cadeira A causou menos desconforto e dor e mais satisfação com os critérios ponderados pelos colaboradores voluntários, já que possuía rodizio, facilitando a movimentação do trabalhador.

\section{Base B}

A cadeira $\mathrm{B}$ que possuía quatro pontos na base foi alvo de diversas reclamações relacionadas à movimentação. Os voluntários enfatizaram principalmente o fato desse mobiliário não proporcionar mobilidade, concordando com as pesquisas de Moraes; Mont'alvão ${ }^{25}$, que relatam a relação dos rodízios à possibilidade de movimentar-se sem a necessidade de levantar-se da cadeira durante a realização da tarefa.

\section{Assento}

$\mathrm{O}$ assento deve ser adequado à natureza da tarefa e às dimensões antropométricas da população. Não existe uma cadeira que seja ergonômica, independentemente da função exercida pelo trabalhador ${ }^{26}$. Cabe à organização prover assentos adequados, seguros e confortáveis ao trabalhador.

\section{Assento A}

Durante a realização do experimento, a cadeira avaliada possuía uma largura de $45 \mathrm{~cm}$, medida superior à encontrada na literatura de revisão, no qual o mínimo era de $33 \mathrm{~cm}$ e o máximo de $43,2 \mathrm{~cm}$. Entretanto, cerca de 93\% da população pesquisada que utilizava essa cadeira aprovava o assento, $5 \%$ achavam desconfortável e 3\% não sabiam opinar.

\section{Assento B}

O dispositivo B possuía um assento de $35 \mathrm{~cm}$, recomendado na literatura, mesmo assim, obtiveram inúmeras críticas dos trabalhadores, relacionadas ao assento, que iam desde o conforto da espuma até a sua largura. Para este item houve $85 \%$ de rejeição; $10 \%$ de aprovação e 5\% não souberam opinar.

\section{Base e apoio de braço}

De acordo com Guimarães ${ }^{13}$, pode-se constatar que, pelo fato de não haver semelhanças nas estruturas dimensionais das bancadas não se pode comparar os resultados obtidos em relação aos apoios de braços e à base.

\section{Apoio para braços $A$}

As cadeiras consideradas melhores não possuíam apoio para braços (cadeira A). Esse fator esta relacionado ao tipo de bancada utilizada para o desenvolvimento do trabalho. 
Outra questão observada na avaliação da cadeira A foram os níveis baixos de reclamações relacionadas às dores/desconfortos apresentados durante o uso desse mobiliário, no qual $50 \%$ dos usuários relataram não sentirem dores ou desconforto no ombro e $60 \%$ no cotovelo, ao utilizarem o assento.

\section{Apoio para braços B}

A cadeira $\mathrm{B}$, que possuía apoio para braços, foi considerada a pior pelos colaboradores, principalmente por não permitir a aproximação junto à bancada, ocasionando dores ao longo dos membros superiores, mais frequente nos ombros e cotovelo devido à má postura adotada ao longo da jornada de trabalho.

Na primeira avaliação, para o item Ombro, 43\% dos entrevistados afirmaram sentir muita dor ao utilizar a cadeira.

Ainda no item Ombro, a cadeira B obteve um total de $39 \%$ de rejeição dos entrevistados, os quais afirmaram que sentiam dores ao utilizar a cadeira em teste. No item Cotovelo, $41 \%$ dos entrevistados relataram sentir muita dor, já $37 \%$ sentiam apenas dores e $21 \%$ somente desconforto.

\section{Os encostos $A$ e $B$}

O encosto possui a função de ajudar no relaxamento, diante a fadiga provocada pelo esforço durante a manutenção da postura na posição sentada. Inicialmente foram verificadas as medidas do encosto em relação aos itens: altura, largura e profundidade, a partir dos estudos de Grandjean ${ }^{16}$, Guimarães ${ }^{13}$, Moraes e Pequini ${ }^{7}$, Panero e Zelnik ${ }^{1}$.

\section{Encosto A}

O mobiliário A foi consideradoo melhor, pois possuía a altura regulável do encosto entre 56 e $65 \mathrm{~cm}$.

Quanto à largura do encosto, convém observar que a cadeira A possuía $44,3 \mathrm{~cm}$ de largura e a cadeira B, $41 \mathrm{~cm}$. A largura máxima recomendada para cadeiras de escritórios de acordo com Guimarães ${ }^{13}$ é de $41 \mathrm{~cm}$; e para Panero e Zelnik ${ }^{1}$ a medida mínima é de 25,4 cm. Outros autores também afirmam que a largura do encosto pode ser de no máximo, $45,7 \mathrm{~cm}$.

\section{Encosto B}

$\mathrm{Na}$ aplicação de entrevista estruturada, observou-se a necessidade de se oferecer uma cadeira com curvatura no apoio lombar do encosto, pelas queixas mais elevadas de desconforto/dor na região lombar, durante a utilização da cadeira B que não possuía tal suporte.
As cadeiras com encosto arredondado foram consideradas as melhores. Isto ocorreu, provavelmente, porque o encosto arredondado ou trapezoidal, que possui curvatura no apoio lombar, proporciona mais espaço para movimento dos ombros e braços, do que o quadrado e reto, permitindo, dessa forma, alternâncias de postura, além de oferecer maior suporte à coluna vertebral na altura da curvatura lombar, como recomenda Guimarães ${ }^{13}$ e Brasil ${ }^{26}$. Deste modo, parecem ser mais apropriadas para trabalhos em posição estática e dinâmica, como a posição dos digitadores, que utilizam os membros superiores, de forma incessante durante as seis horas.

As cadeiras com encosto baixo de 41,9 a $55 \mathrm{~cm}$ foram consideradas as piores (cadeira B) e a literatura indica para trabalhos dinâmicos, a altura do encosto com no mínimo $56 \mathrm{~cm}$.

Desta forma, pode-se afirmar que a cadeira B não atendeu satisfatoriamente às necessidades dos colaboradores desse setor especifico, embasando a importância de um mobiliário adequado para cada tipo de atividadedesempenhada pelo trabalhador.

Nesta análise, recomenda-se uma cadeira giratória com rodízios, destinada ao setor de digitação da CODOC.

\section{CONSIDERAÇÕES FINAIS}

Conclui-se atravésda metodologia pesquisada que a partir dos aportes científicos da engenharia de produção, do design, incluindo a interface com a tecnologia assistiva e a ergonomia foi possível a construção de um suporte teórico como recomendação e construção da proposta de escolha uma cadeira adequada, por meio do uso dos resultados da utilização da avaliação de desconforto e dor e de satisfação da cadeira através de entrevista semiestruturada.

Assim, o estudo da postura na clínica de to set and position, utilizado por terapeutas ocupacionais na área de Tecnologia Assistiva reflete nas recomendações de futuras escolhas das cadeiras, considerando o estabelecimento da relação entre a postura sentada e as necessidades do indivíduo, a partir dos dois tipos de cadeiras estudadas, e que, por ser um mobiliário de venda comum no Brasil, são encontradas nos escritórios e nos setores de serviços.

Após a realização da pesquisa, definiu-se a importância do SAP, adequado ao tipo de atividade realizada, preservando a biomecânica do usuário, como forma de minimizar a possibilidade de elevação dos níveis de desconforto e dor, tratando esses itens percussores dos DORT na Autarquia pesquisada.

É reconhecida a importância de selecionar uma cadeira adequada para o desempenho de atividades de 
precisão, como é o caso do trabalho informatizado, além de considerar a longa jornada de trabalho realizada na posição sentada, diminuindo os custos humanos e o efeito de doenças decorrentes do trabalho.

\section{REFERÊNCIAS}

1. Panero J, Zelnik M. Las dimensiones humanas em los espacios interiores. México, DF: Gustavo Gili; 1993.

2. Iida I. Ergonomia projeto e produção. São Paulo: Edgard Blücher; 2005.

3. Silva EM. Avaliação da preferência de cadeiras para diferentes tipos de trabalhos de escritório [Dissertação]. Porto Alegre: Faculdade de Tecnologia da Universidade Federal do Rio Grande do Sul; 2003.

4. Brasil. Ministério da Previdência Social, Ministério do Trabalho e Emprego. Anuário estatístico de acidente de trabalho 2010-2012. Brasília: Ministério do Trabalho e Emprego; 2012.

5. Daldon MTB, Lancman S. Terapia ocupacional na vigilância em saúde do trabalhador. Rev Ter Ocup Univ São Paulo. 2012;23(3):216-22. http://dx.doi.org/10.11606/issn.22386149.v23i3p216-222.

6. Gomez C, Costa SMF. A construção do campo da saúde do trabalhador: percurso e dilemas. Cad Saude Publica. 1997;13(2):21-32. http://dx.doi.org/10.1590/S0102311X1997000600003.

7. Moraes A, Pequini SM. Ergodesign para terminais informatizados. Rio de Janeiro: 2AB; 2002.

8. Lancman S, Ghirardi MIG. Pensando novas práticas em terapia ocupacional, saúde e trabalho. Rev Ter Ocup Univ São Paulo. 2002;13(2):44-50. http://dx.doi.org/10.11606/ issn.2238-6149.v13i2p44-50.

9. Brasil. Ministério da Indústria, Desenvolvimento e Comércio Exterior (MIDC). Superintendência da Zona Franca de Manaus (SUFRAMA). Novo Processo de Internamento de Mercadorias Nacionais - Sistemas de Controle de Ingresso de Mercadoria Nacionais - SINAL [citado 12 out. 2010]. Disponível em: http://www.slideshare.net/denisfiscal/ suframa-passo-a-passo-remetente.

10. Barroso BIL. Avaliação da sensação de desconforto e de dor durante a postura sentada: uma análise em terminais informatizados [Dissertação]. Manaus: Faculdade de Tecnologia, Universidade Federal do Amazonas; 2010.

11. Silva EL, Menezes EM. Metodologia da pesquisa e elaboração de dissertação. Florianópolis: Laboratório de Ensino a Distância da UFSC; 2003.
12. Iida I, Pazzeto VMF. Qualidade dos móveis para informática: cadeiras. In: $4^{\circ}$ Congresso Brasileiro de Pesquisa e Desenvolvimento em Design, Rio de Janeiro, 1998. Anais... Rio de Janeiro; 1998. p.153-9. Disponível em: http://minhateca.com.br/Marcos.Pelegrini/ Arquivos + Diversos + SST/Arquivos/Qualidade $+\mathrm{de}+\mathrm{m} * \mathrm{c} 3 *$ b3veis+para+inform*c3*a1 tica+cadeiras,322858010.pdf.

13. Guimarães LBM. Ergonomia de produto. $2^{\mathrm{a}}$ ed. Porto Alegre: UFRGS; 2001. Disponível em: http://www.producao.ufrgs. br/arquivos/disciplinas/499_ergproduto.pdf.

14. Cooper DR, Schindler PS. Métodos de pesquisa em administração. 7a ed. São Paulo: Bookman; 2003.

15. Yin RK. Estudo de caso - planejamento e métodos. 2a ed. Porto Alegre: Bookman; 2001.

16. Grandjean E. Manual de ergonomia: adaptando o trabalho ao homem. Porto Alegre: Bookman; 1998.

17. Löbach B. Design industrial: bases para a configuração dos produtos industriais. São Paulo: Editora Blucher; 2001.

18. Associação Brasileira de Normas Técnicas (ABNT). NBR 13962: móveis para escritórios: cadeiras. Rio de Janeiro; 2002.

19. Floyd WF. Anatomical, physiological and anthropometric principles in the design of office chairs and tables. BS. London: British Standards Institution; 1958.

20. Brasil. Ministério do Trabalho. Manual de aplicação da norma regulamentadora $\mathrm{n}^{\mathrm{o}}$ 17. $2^{\mathrm{a}}$ Ed. Brasília: TEM/SIT; 2002. Disponível em: http://portal.mte.gov.br/data/files/ 8A7C816A3DCAE32F013DCBE7B96C0858/pub_cne manual_nr17\%20\%28atualizado_2013\%29.pdf.

21. Straker LM. Body discomfort assessment tools. In: Karwowski W, Marras WS, editors. The occupational ergonomics handbook. London: CRC; 2000. p.1239-52.

22. Corlett EN, Wilson JR, Manenica I. The ergonomics of working postures. London: Taylor \& Francis; 1986.

23. Alencar MCB, Biz RAM. Relações entre condições e organização do trabalho e os afastamentos de trabalhadores portuários de transporte. Rev Ter Ocup Univ São Paulo. 2012;23(3):208-15. http://dx.doi.org/10.11606/issn.22386149.v23i3p208-215. 
Barroso BIL, Galvão CRC. Múltiplas avaliações para aquisição de cadeiras. Rev Ter Ocup Univ São Paulo. 2015 jan./abr.;26(1):136-45.

24. Souza MBCA, Marcolino AV, Nascimento RL, Oliveira ER, Souza EL, Barroso BIL. Investigação sobre a satisfação e os efeitos de móveis utilizados por estudantes universitários. Rev Ter Ocup Univ São Paulo. 2014;25(3):289-98. doi: http://dx.doi.org/10.11606/issn.2238-6149.v25i3p289-298.
25. Moraes A, Mont'alvão C. Ergonomia: conceitos e aplicações. Rio de Janeiro: 2AB; 2000.

26. Brasil. Ministério do Trabalho e Emprego (TEM). Secretaria de Inspeção do Trabalho. Nota técnica 060/2001. Brasília; 2002.

Recebido para publicação: 13/08/2013

Aceito para publicação: 12/11/2014 